\title{
Effect of PMF length to channel spacing tunability by temperature in multiwavelength fiber laser
}

\begin{abstract}
A channel spacing tunability of multiwavelength fiber laser (MWFL) based on bidirectional Lyot filter and semiconductor optical amplifier (SOA) is demonstrated. The birefringence value of polarization maintaining fiber (PMF) is temperature dependence, thus by heating the PMF, the channel spacing is narrower. From the experimental data, the temperature coefficient based on PMF length of $53.2 \mathrm{~m}$ and $10.6 \mathrm{~m}$ is $0.49 \times 10-3 \mathrm{~nm} /{ }^{\circ} \mathrm{C}$ and $1.35 \times 10-3$ $\mathrm{nm} /{ }^{\circ} \mathrm{C}$, respectively, thus shorter PMF is more sensitive to temperature.
\end{abstract}

Keyword: Multiwavelength fiber laser; Lyot filter; Intensity dependent loss; Semiconductor optical amplifier 